\title{
Dos
}

\section{Ciencias satelitales \\ e inclusión social}

DOI: 10.29236/sistemas.n157a7

Satélites sociales e Ingenieros sin fronteras hacia la inclusión social.

\section{Manuel Dávila Sguerra}

La Unión Europea define la inclusión social como un "proceso que asegura que aquellas personas que están en riesgo de pobreza y exclusión social tengan las oportunidades y recursos necesarios para participar completamente en la vida económica, social y cultural disfrutando un nivel de vida y bienestar que se considere normal en la sociedad en la que ellos viven". Hace énfasis en el derecho de las personas de "tener una vida asociada siendo un miembro de una comunidad" (Andalucía solidaria, 2020).
El tema satelital aparece porque a través de los satélites es posible estudiar el estado de la tierra y dirigir los resultados de estos análisis a los agricultores y, en general, a las comunidades relegadas para controlar sus propios territorios.

\section{Ingeniería humanitaria}

La Ingeniería Humanitaria se está convirtiendo en un "eEstado del arte" que, de acuerdo con información conocida de la Universidad Sergio Arboleda (U Sergio Arboleda, 2020), la Universidad Nacional 
y lo estudiado en el Parque Científico de Innovación Social de Uniminuto, entre otros, está relacionada con el uso de metodologías participativas que vinculan a las comunidades con las teorías científicas y desarrollos tecnológicos.

La ruta del Parque Científico de Innovación Social de Uniminuto muestra que para desarrollar proyectos es necesario alistar, entender, analizar, crear, implementar, empaquetar y escalar para que las soluciones sean instauradas y apropiadas colectivamente en el territorio en el que fueron implementadas, para adaptarlas en otros contextos. En tal sentido, se trata de buscar la resolución de problemas sociales y ambientales, además del diseño y evaluación de proyectos con impacto social. Así mismo, es necesario formar profesionales conscientes de la naturaleza cambiante del entorno y entrenarlos para la resolución de las necesidades básicas de las comunidades en situaciones de vulnerabilidad social, ambiental y económica, así como lograr el empoderamiento y su autorreplicación. El profesor Ismael Peña de la Universidad Nacional dice sobre la Ingeniería Humanitaria en una de sus publicaciones (Research, 2015):

"De acuerdo con Munoz \& Skokan (2007, quien cita a Cuny (1983)) se identifican tres ambientes de operación de la ingeniería humanitaria, el primero es respuesta a emergencias, el segundo es respuesta para el desarrollo y en medio sitúa la respuesta transicional. Por su parte Conkol (2012), establece tres escenarios de acción, a) Recuperación de desastres, b) Desarrollo y c) Re-desarrollo. Mientras, Kinsner (2014) plantea cuatro niveles de acción, a) Desastres naturales (incendios, tormentas, tornados, tsunamis, terremotos, inundaciones), b) Crisis humanitarias (genocidios, guerras, elecciones no democráticas, injusticia), c) Países en vía de desarrollo (agua, alimentos, refugio, energía, saneamiento, salud), y d) Países desarrollados (comunidades pobres, envejecidos, personas con discapacidad mental-física, comunidades no representadas)".

Estas y otras reflexiones han llevado al Parque Científico de Innovación Social de Uniminuto a crear un proyecto llamado "Satélites sociales" el cual se ha ligado al grupo de Ingenieros sin fronteras de la misma entidad. El tema satelital puede aparecer alejado de la inclusión social, pero, cuando se definen centrados en el ser humano y en especial en las personas más necesitadas, cobra el valor social y favorece la inclusión como iremos viendo (PCIS, 2020e).

\section{CubeSat social}

Este proyecto tiene el reto estratégico de la puesta en órbita de un satélite tipo CubeSat que contribuya al desarrollo científico y social del país. El CubeSat es un satélite que entra dentro de la clasificación de 
Nanostélite y puede tener varios tamaños, "pero todos se basan en la unidad estándar de CubeSat, que es una estructura en forma cubo de $10 \times 10 \times 10$ centímetros con una masa de aproximadamente de entre 1 y 1,33 kg. Esta unidad es conocida como 1U. Tras los primeros años, esta unidad modular se fue multiplicando y tamaños más grandes de nanosatélites se han vuelto habituales (1.5U, 2U, 3U o 6U). Actualmente se siguen desarrollando nuevas configuraciones" (Alen, 2020).

Tomado de la misma página web del Parque Científico de Innovación Social de Uniminuto, esta institución explica su interés en este concepto, orientado hacia la inclusión social:

"El interés del Parque Científico de Innovación Social -PCIS- en el tema satelital es desarrollar desde Ingenieros sin Fronteras el concepto ISFCOL - CubeSat Social, identificando oportunidades de aplicaciones humanitarias en Colombia desde las diversas entidades que conforman el Minuto de Dios y el desarrollo de capital humano en ciencia y tecnología que promueva la investigación y el desarrollo de aplicaciones espaciales para la solución de problemáticas del país. El trabajo se está realizando entre Uniminuto y la Corporación Educativa Minuto de Dios CEMID. Desde la primera, participa el PCIS con las unidades STEM Robotics, Ingenieros Sin Fronteras y las faculta- des de Ingeniería de Sede Principal" (Ifcol CubeSat Social, 2020).

Al lado de esta unidad existe otra llamada "Imágenes satelitales" que corresponde a la lectura de los datos de los satélites para darles las interpretaciones adecuadas y comprender qué es lo que observamos de la tierra, basados en los satélites Sentinel del proyecto Copernicus de la Unión Europea.

\section{Lectura de las imágenes satelitales}

La Unión Europea ha abierto las bases de datos de su proyecto Copérnicus a nuestros países, dando la oportunidad de leer los datos de los territorios colombianos (Copernicus, 2020). Los satélites son observadores de las regiones en donde se asientan las comunidades, lo que hace posible desarrollar proyectos para la vigilancia de la agricultura y georreferenciación de cultivos (PCIS, 2020a), el análisis de zonas incendiadas (PCIS, 2020d) y la búsqueda de patrones para crear planes de contingencias, evidenciar hundimiento de territorios, estudiar la calidad del aire medido en concentraciones de aerosoles (PCIS, 2020f) o de No2 (PCIS, 2020b), asuntos de deforestación (PCIS, 2020c), estudios de la calidad del agua y determinación y trazado de cuerpos húmedos con máxima precisión, entre otras alternativas.

Valga decir que los satélites no ven cosas, lo que hacen sus sensores es detectar las imágenes de luz que 
deben ser procesadas con algoritmos apropiados, basados en las leyes del electromagnetismo, dependiendo de lo que se quiere trabajar; y son imágenes que nos representan los estados de la tierra para que las comunidades conozcan esas transformaciones.

\section{Ejemplos de imágenes dentro del concepto de satélites sociales}

\section{Determinación de zonas Acuíferas}

Se trata de hacer seguimientos a las zonas acuíferas y determinar pérdidas de masas de agua, elemento fundamental para los agricultores. Las imágenes transmitidas bajo las bandas del color natural Rojo, Verde y Azul pueden confundir zonas que parecen agua, de otras que no lo son. Por eso es ne- cesario aplicar algoritmos de filtros para detectar, de manera segura, zonas acuíferas y estudiar sus transformaciones. En el gráfico 1 se muestra el diagrama de flujo del algoritmo para tal fin.

\section{Análisis de hundimiento de tierras}

En el caso de los sismos se crean desplazamientos que se pueden analizar utilizando satélites con sensores de radar como es el caso del Sentinel - 1 del proyecto Copérnicus. En la gráfica 2 presentamos el diagrama de flujo del algoritmo para el análisis del sismo de 4.8 del 22 de Julio de 2020 en Los Santos, departamento de Santander en Colombia.

El último mapa muestra el resultado final de este complejo algoritmo; al recorrerlo con el mouse, espe-

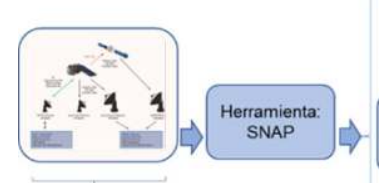

Misiones
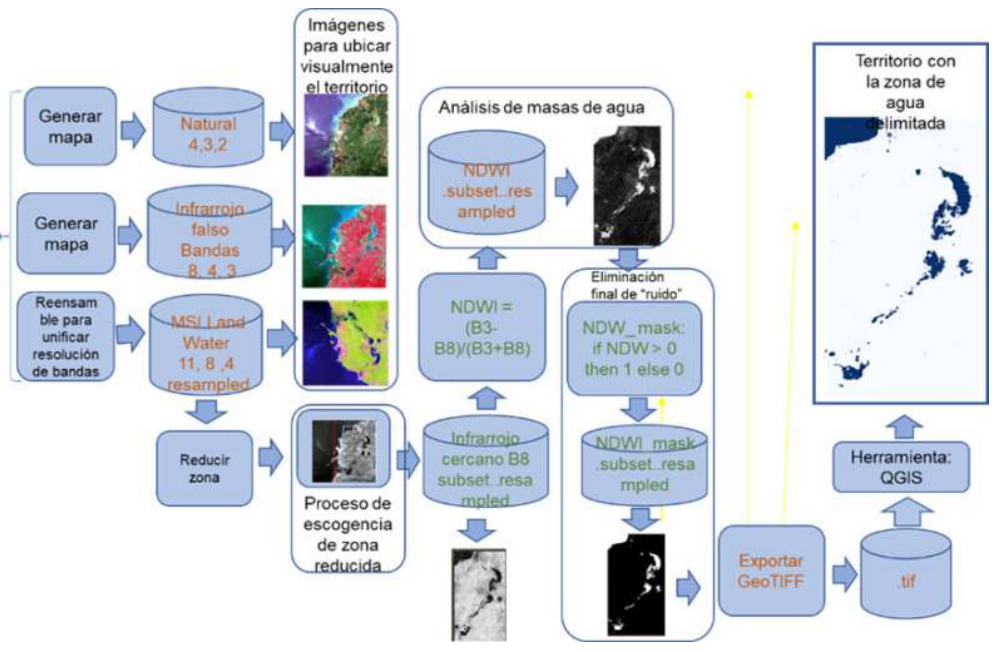

QGIS

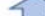

Gráfica 1. Algoritmo para determinar zonas acuíferas en María la Baja Colombia-. Fuente: PCIS - Uniminuto 


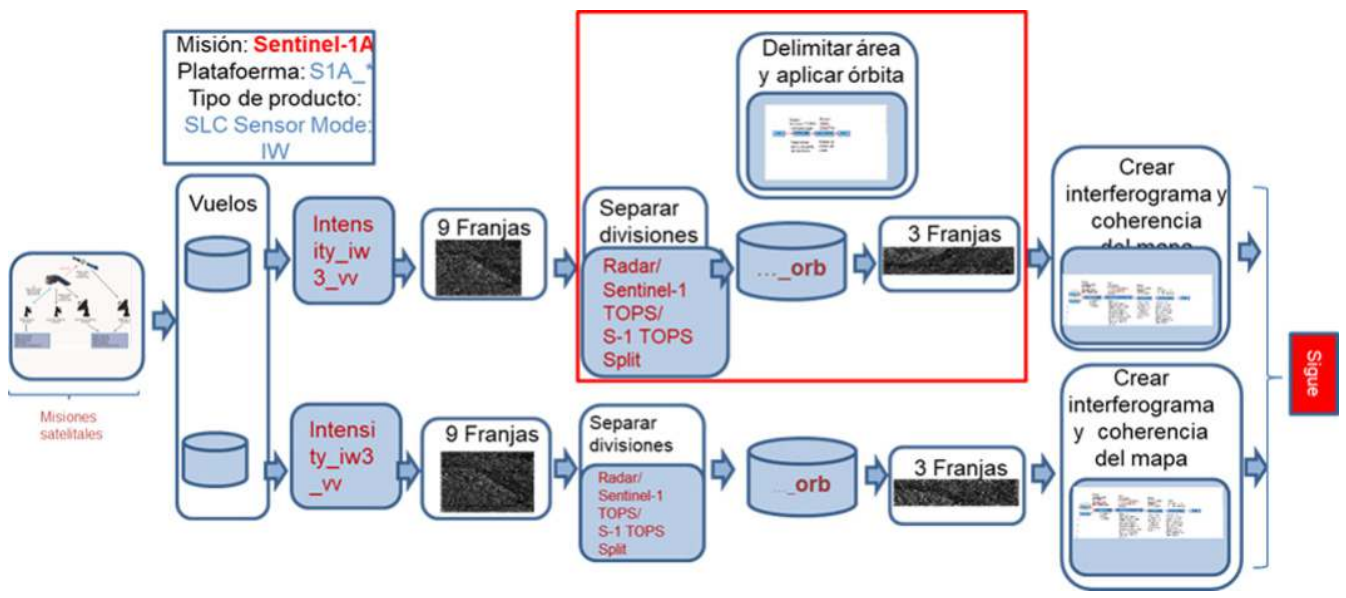

Grafica 2. Algoritmo para determinar hundimientos de terrenos, en este caso del sismo en Los Santos, Santander Colombia, Interferograma - Fase I. Fuente PCIS

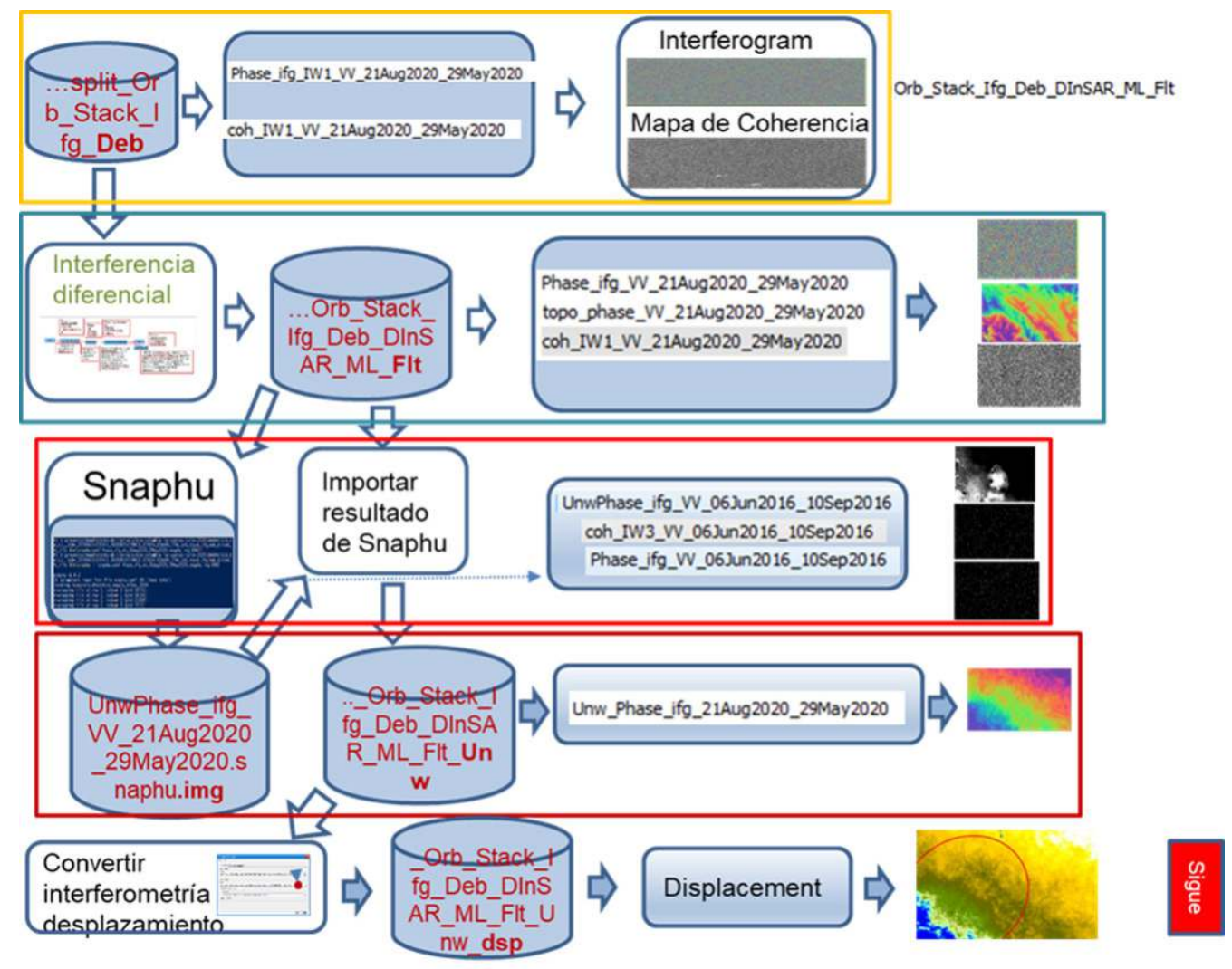

Grafica 3. Algoritmo para determinar hundimientos de terrenos, en este caso del sismo en Los Santos, Santander Colombia, desplazamientos de tierra Fase II. Fuente PCIS 
cialmente en las zonas azules, se podrán leer los niveles de desplazamientos en fracciones de metros por pixel. Al aplicar series de tiempo y revisar fechas sucesivas es posible medir el estado de hundimiento de los futuros cercanos y prevenir desastres.

\section{Estudio de la calidad del agua}

El estudio del agua está relacionado con el análisis de las propiedades ópticas inherentes que son aquellas representaciones en forma de ondas de luz de la clorofila, del material suspendido y de otras propiedades del agua y de sus costas que muestran los instrumentos multiespectrales. El caso de la Laguna de Tota es muy representativo por los cultivos de cebolla alrededor de la laguna y, si estos resultados muestran a las comunidades, se tendría la oportunidad de regular esos procesos que pueden acabar con la laguna. El algoritmo aplicado en este caso que también es replicable en otras zonas de agua dulce se muestra en la gráfica 4 .

Los mapas finales que son el resultado de este algoritmo muestran el estado de la Laguna en seis lecturas diferentes y fechas distintas, y permiten analizar pérdida o ganancia de clorofila, de material suspendido, casi invisible al ojo humano y otros aspectos que conforman las ya mencionadas propiedades ópticas inherentes.

\section{Calidad del aire antes y} después del coronavirus

El aire que respiramos está haciendo daño a la salud de las personas. En Uniminuto pensamos que este tipo de estudios unidos a campañas que podrán realizarse pueden concientizar a los habitantes de una región o de una ciudad para que protejamos el medio ambiente y la salud de las personas.
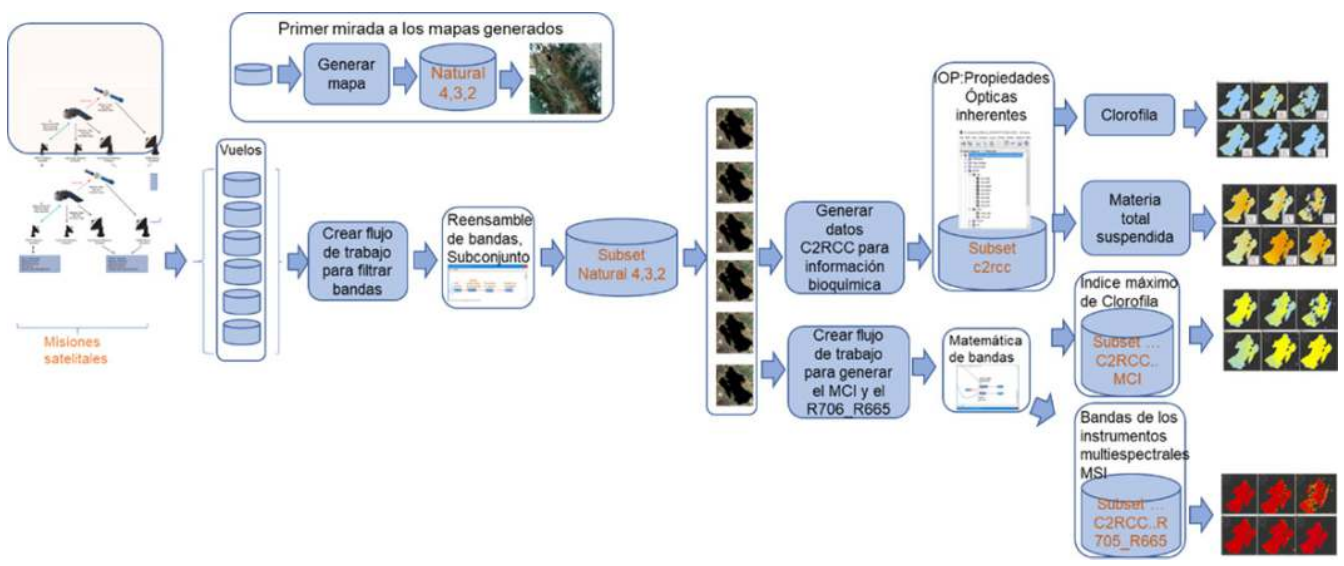

Gráfico 4. Algoritmo para hacer análisis de calidad de Agua y propiedades ópticas inherentes de la Laguna de Tota. Fuente PCIS 
La pandemia nos enseñó aún más los daños que le hacemos al aire especialmente en las ciudades. Eso lo hemos notados a simple vista, pero con el uso de los satélites, en este caso del Sentinel - 5 nos pusimos en la tarea de medir la diferencia de calidad del aire antes y después del coronavirus obteniendo resultados impresionantes. Para eso seguimos más de 15 vuelos de este satélite, que le da vueltas a la tierra de polo a polo mientras ella gira en su eje, permitiendo medir de sur a norte los estados del aire de los cinco continentes. En Colombia tomamos la imagen de la gráfica 5 sobre la zona de Bogotá que muestra la diferencia de calidad del aire.

Como ejemplo de estos resultados, la gráfica 6 muestra la comparación de la franja de América con la diferencia de calidad de aire que, visto de otra manera, es el tamaño del daño que estamos haciendo por la generación de las partículas aerosol.

Este tipo de análisis está dirigido a la salud de las comunidades y el hecho de que la academia pueda estar involucrada en estos estudios abre la posibilidad para hacer intervenciones orientadas al bienestar de los habitantes de estas ciudades.

\section{Relación entre la polución con NO2 y los contagios con el coronavirus}

Los científicos comentaron que puede existir una relación entre la polución de $\mathrm{NO} 2$ de las ciudades $\mathrm{O}$ en zonas de incendios y las probabilidades de contagio con el coronavirus. El análisis se hizo para todo el mundo. No se puede aseverar que lo indicado por los científicos sea una realidad, pero los observadores pueden juzgar y tomar sus propias conclusiones.

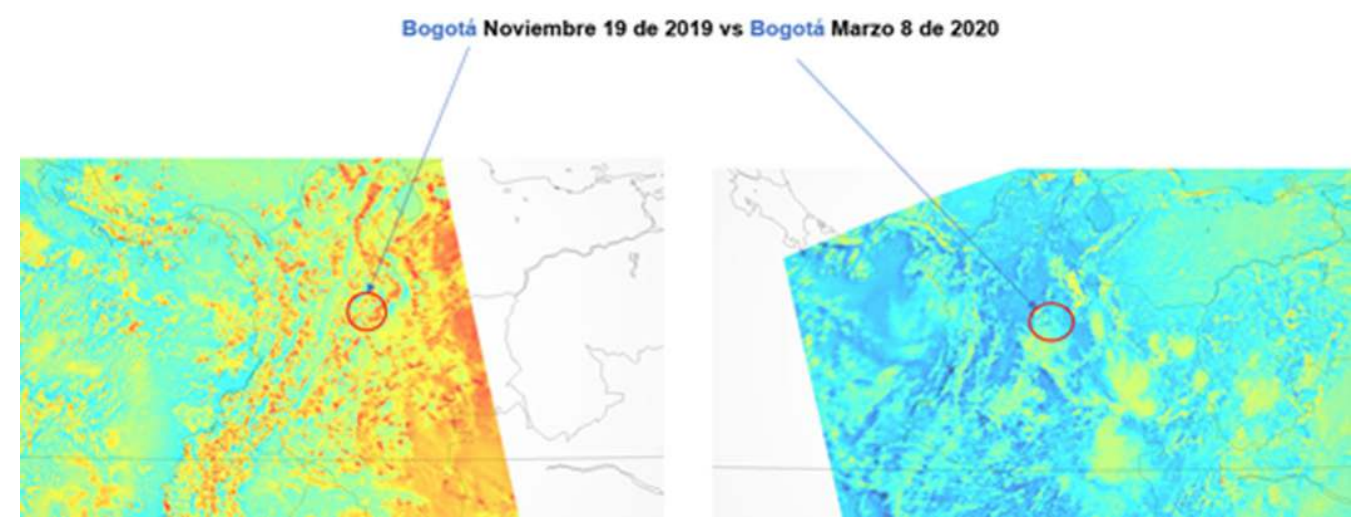

Gráfico 5. Análisis de la calidad de aire en la Zona de Cundinamarca antes y después del Corona Virus. Fuente PCIS 


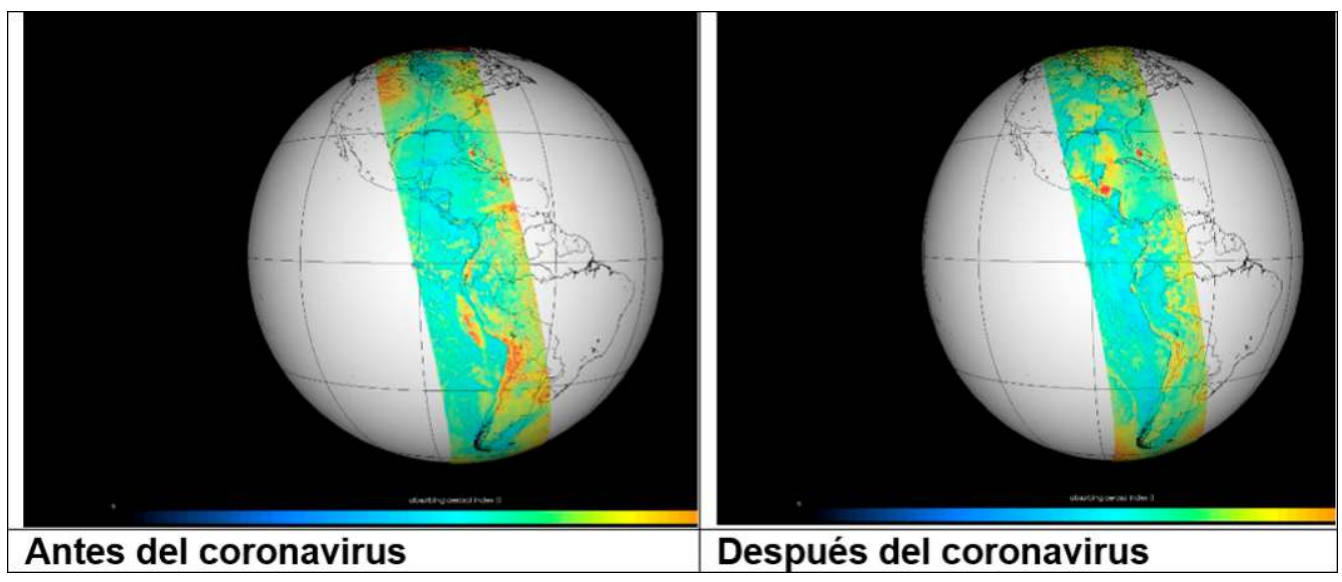

Gráfico 6. Análisis de la calidad de aire en la franja de América antes y después del Corona Virus. Fuente PCIS

Incendios en áreas rurales

En marzo de este año se conoció una noticia sobre la excesiva polución en el aire de Cúcuta producto -se cree- de un incendio en el Cata- tumbo. EI PCIS hizo un análisis cuyos resultados se muestran en el gráfico 7. Está experiencia está dentro de los planes para estudiar más detenidamente los incendios,

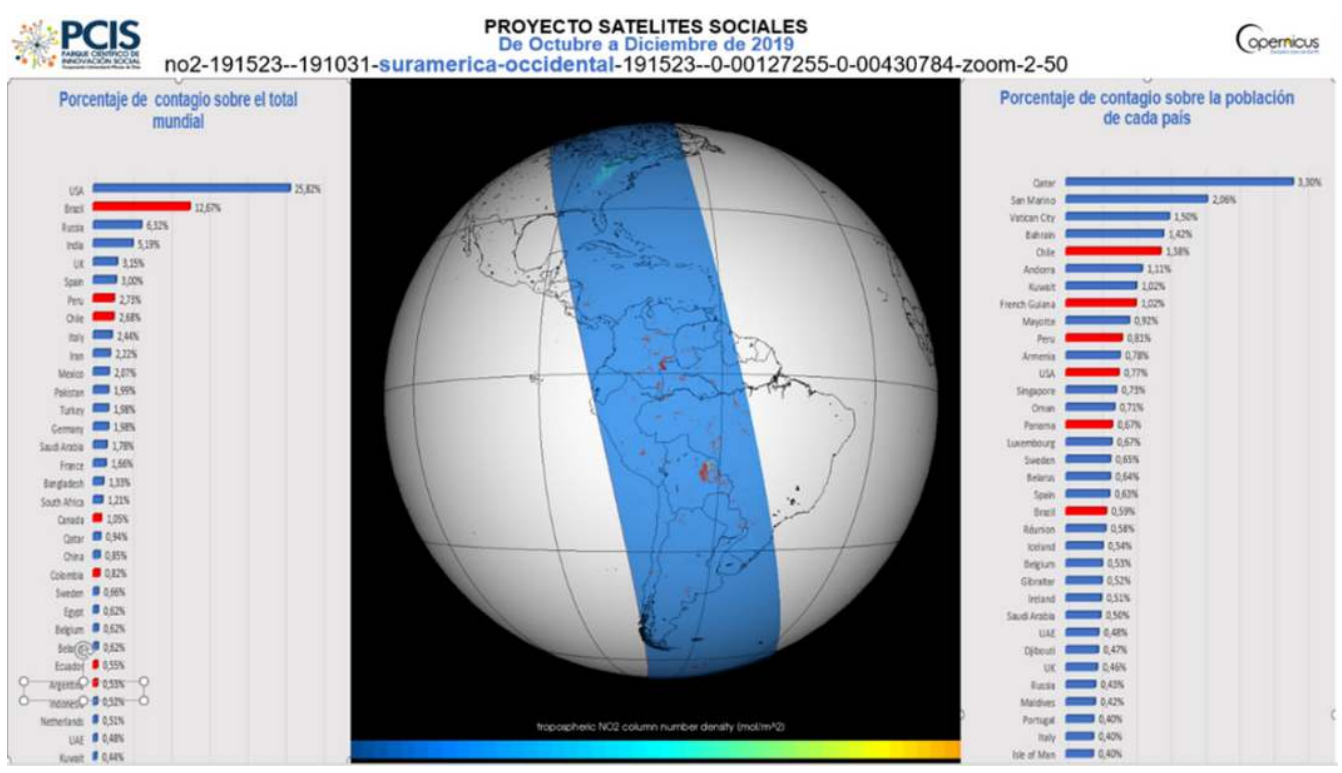

Gráfico 7. Relación entre polución NO2 y contagios del Corona Virus, Zona occidental de América, incluida Colombia. A la izquierda estadísticas sobre los porcentajes de contagio de cada país sobre el total mundial. A la derecha porcentaje sobre su propia población. Fuente PCIS 

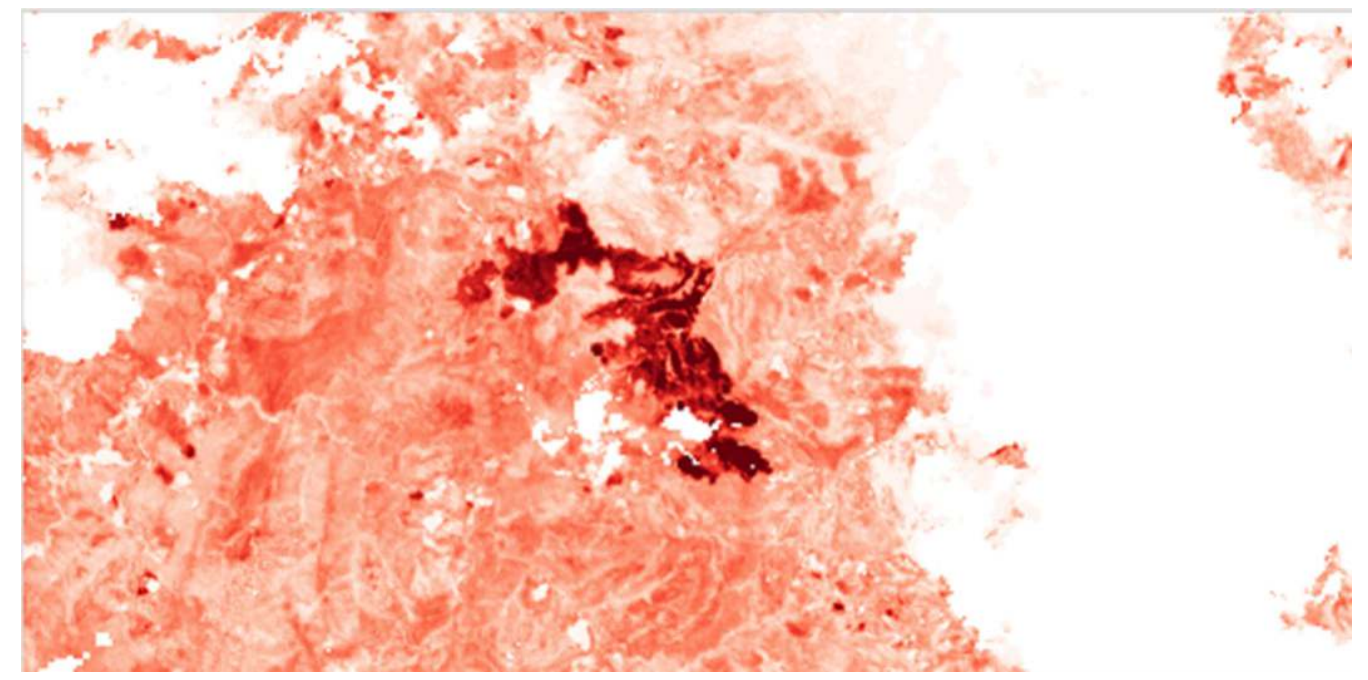

Gráfica 8. Resultado del análisis del incendio en Catatumbo que creo problemas en el aire de Cúcuta. Fuente PCIS

usando series de tiempo para medir la frecuencia de estas ocurrencias en varios territorios que permita generar patrones de comportamiento de la naturaleza y plantear planes de contingencia.

Las imágenes deben ser filtradas a través de algoritmos que nos lleven representaciones reales, en este caso de zonas incendiadas que permitan medir áreas y perímetros de daños generados por las conflagraciones. Así, los resultados de los análisis de las imágenes satelitales nos dan información que, aplicada para temas de orden social como las mencionadas, ayudan a las comunidades para que no estén desprotegidas frente a los eventos de la naturaleza que afectan su vida de manera directa.

\section{Conclusiones}

En la comunidad académica colombiana hemos trabajado mucho el tema de Universidad, Empresa y Estado. Con el tiempo y teniendo en cuenta la extensión de las nuevas tecnologías hacia la sociedad misma ahora hablamos de Empresa, Universidad, Estado y Sociedad. Uno de los temas más delicados de la sociedad colombiana es la estratificación social tan marcada, producto de nuestra historia "virreinal" con una marca que crea diferencias no solo en lo económico, sino de sangre y de linaje. Esta situación hace invisible a mucha parte de nuestra población y es ahí en donde tratamos de influir con el proyecto de Satélites Sociales.

Para lograr resultados que impacten es necesario formar profesionales e incentivar la creación de semilleros de investigación que vayan apropiándose de estos conocimientos, para crear proyectos con las comunidades impactadas, especialmente en temas que como 
este, no están aún apropiados por la academia colombiana. De hecho, se están preparando 20 profesores de todo el sistema, que incluye regiones de Cundinamarca, Tolima y Magdalena Medio, Bogotá, Regional Orinoquía, Eje Cafetero, Antioquía, Chocó, Villavicencio, Zipaquirá, Cúcuta, Bucaramanga y Eje Cafetero, lugares en donde Uniminuto está presente a nivel nacional.

\section{Referencias}

Alen. (2020). Guía básica de Nanosatélites. Recuperado el 9 de octubre de 2020 de https://alen.space/es/guia-ba sica-nanosatelites/

Andalucía Solidaria. (2020). Inclusión Social. Recuperado el 9 de octubre de 2020 de http://www.andaluciasolida ria.org/que-hacemos/inclusion-social

Conkol, G. K. (2012). Humanitarian Engineering - Emerging Technologies and Humanitarian Efforts. Proceedings of IEEE Global Humanitarian Technology Conference (pp. 253-258). IEEE.

Copernicus. (2020). Copérnicus, Recuperado el 9 de octubre de https://www.copernicus.eu/es

(Ifcol CVubeSat Spcial. (2020). Ingenieros sin fronteras. Recuperado el 9 de octubre de 2020 de https://eventos.uni minuto.edu/53316/section/25988/inge nieros-sin-fronteras-colombia.html

Ifcol CVubeSat Spcial. (2020). Ingenieros $\sin$ fronteras. Recuperado el 9 de octubre de 2020 de https://eventos.unimi nuto.edu/53316/section/25988/ingenie ros-sin-fronteras-colombia.html

Kinsner, W. (2014). HUMANITARIAN ENGINEERING EDUCATION: EXAMPLES. En 2014 Canadian Engineering
Education Association (pp. 1-6). Canmore.

Munoz, D. and Skokan, C. K. (2007). Humanitarian engineering programme: conceptual challenges. World Transactions on Engineering and Technology Education, Vol. 6, No 2, pp. 253-256.

PCIS. (2020a). Análisis del territorio de Cundinamarca con cultivos de guadua. Recuperado el 11 de octubre de 2020 de http://www.uniminuto.edu/web/pc is/mapas-satelitales/-/asset_publi sher/a64ahFMouwal/content/analisisdel-territorio-de-cundinamarca-concultivos-de-guadua?inheritRedirect= false\&redirect $=$ http $\% 3 \mathrm{~A} \% 2 \mathrm{~F} \% 2 \mathrm{Fwww}$ .uniminuto.edu $\% 2 \mathrm{Fweb} \% 2 \mathrm{Fpcis} \% 2 \mathrm{~F}$ mapas-satelitales $\% 3 F p \_p \_i d \%$ 3D101_INSTANCE_a64ahFMouwal\% 26p_p_lifecycle\%3D0\%26p_p_state $\%$ 3Dnormal\%26p_p_mode\%3Dview\%2 $6 p \_p \_c o l$ id $\% 3 D$ column-1\%26p_p_ col_count\%3D1

PCIS. (2020b). NO2 y Coronavirus. Recuperado el 11 de octubre de 2020 de http://www.uniminuto.edu/web/pcis/ma pas-satelitales/-/asset_publisher/ a64ahFMouwal/content/-no2-ycoronavirus-?inheritRedirect=false \& redirect=http $\% 3 \mathrm{~A} \% 2 \mathrm{~F} \% 2 \mathrm{Fwww}$.unimi nuto.edu\%2Fweb\%2Fpcis\%2Fmapassatelitales\%3Fp_p_id\%3D101_INSTA NCE_a64ahFMouwal\%26p_p_lifecycl e\%3D̄0\%26p_p_state\%3Dnormal\%26 p_p_mode $\% 3$ Dview\%26p_p_col_id \% 3Dcolumn-1\%26p_p_col_count\%3ㅁ1

PCIS. (2020c). Deforestación zona del Caguán Colombia. Recuperado el 11 de octubre de 2020 de http://www.unimi nuto.edu/web/pcis/mapas-satelitales//asset_publisher/a64ahFMouwal/cont ent/deforestacion-zona-del-caguancolombia?inheritRedirect=false\&redire ct=http $\% 3 \mathrm{~A} \% 2 \mathrm{~F} \% 2 \mathrm{Fwww}$.uniminuto.e du $\% 2$ Fweb $\% 2$ Fpcis $\% 2$ Fmapassatelitales\%3Fp_p_id\%3D101_INSTA NCE_a64ahFMouwal\%26p_p_lifecycl e\%3D $0 \% 26 p \_p \_s t a t e \% 3 D$ normal\%26 
p_p_mode\%3Dview\%26p_p_col_id\% 3Dcolumn-1\%26p_p_col_count $\% 3 \bar{D} 1$

PCIS. (2020d). Incendio Catatumbo. Recuperado de http://www.uniminuto. edu/web/pcis/mapas-satelitales/lasset_publisher/a64ahFMouwal/cont ent/incendio-catatumbo-2020?inherit Redirect=false\&redirect $=\mathrm{http} \% 3 \mathrm{~A} \% 2 \mathrm{~F}$ $\% 2 \mathrm{Fwww}$ uniminuto.edu\%2Fweb\%2F pcis $\% 2 \mathrm{Fmapas}$-satelitales $\% 3 \mathrm{Fp} \_\mathrm{p}$ id\%3D101_INSTANCE a64ahFMouw al\%26p_p_lifecycle\%3D $0 \% 26 p \_p \_s t a$ te\%3Dnormal\%26p p mode\%3Dview $\% 26 p \_p \_c o l i d \% 3 D$ column-1\%26p_ p_col_count\%3D1

PCIS. (2020e). SaberPCIS Satélites Sociales: Imágenes Para EI Uso Social. Recuperado el 11 de octubre de http:// www.uniminuto.edu/web/pcis/mapassatelitales/-/asset_publisher/a64 ahFMouwal/content/saberpcis-sate lites-sociales-imagenes-para-el-usosoci-1 ? inheritRedirect $=$ false \& re direct=http $\% 3 \mathrm{~A} \% 2 \mathrm{~F} \% 2 \mathrm{Fwww}$.uniminu to.edu $\% 2 \mathrm{Fweb} \% 2 \mathrm{Fpcis} \% 2 \mathrm{Fmapas}-$ satelitales\%3Fp_p_id\%3D101_INSTA NCE_a64ahFMouwal\%26p_p_lifecycl

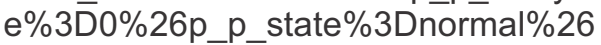
p_p_mode $\% 3$ Dview $\% 26 p \_p \_c o l i d \%$ 3Dcolumn-1\%26p_p_col_count\%3ㅁ1

PCIS. (2020f). Análisis de la calidad del aire polo a polo y detalle del mundo.
Recuperado de http://www.uniminuto. edu/web/pcis/mapas-satelitales/lasset_publisher/a64ahFMouwal/cont ent/analisis-de-la-calidad-del-airepolo-a-polo-y-detalle-del-mundo? inheritRedirect=false \&redirect $=\mathrm{http} \% 3$ A\%2F\%2Fwww.uniminuto.edu\%2Fwe b $\% 2 \mathrm{Fpcis} \% 2 \mathrm{Fmapas}$-satelita les\%3Fp_p_id\%3D101_INSTANCE_a 64ahFMouwal\%26p_p_lifecycle\%3D̄0 $\% 26 p \_p \_s t a t e \% 3 D$ normal\%26p_p_m ode\%3Dview\%26p_p_col_id\%3Dcolu mn-1\%26p_p_col_count\%3D1

Research Gate. (2015). Ingenio y sociedad: hacia una educación de ingeniería humanitaria en Colombia, Recuperado de (https://www.researchgate.net/pro file/Nicolas_Gaitan-Albarracin2/pu blication/328891276_Ingenio_y_Socie dad_Hacia_una_educacion_de_ingeni eria_humanitaria_en_Colombia/links/5 bea0̄a6992851c $\overline{6}$ b2 $\overline{7}$ ba3e6c/Ingenioy-Sociedad-Hacia-una-educacion-deingenieria-humanitaria-en-Colom bia.pdf

U Sergio Arboleda. (2020). Ingeniería Humanitaria, Recuperado el 7 de octubre de 2020 de (https://www.usergioarbo leda.edu.co/centros_e_institutos/inge nieria-humanitaria/)

Manuel Dávila S. Ingeniero de Sistemas de la Universidad de Los Andes. Maestría Cum Laude en Filosofía, Pontificia Universidad Javeriana. Exdecano de la Facultad de Ingeniería de Uniminuto. En la actualidad es miembro de Ingenieros sin fronteras del Parque Científico de Innovación Social de Uniminuto; del grupo Ciudades Inteligentes de RUMBO. Es miembro fundador de la Asociación de Industriales de Software (Indusoft hoy Fedesoft); de la Asociación Colombiana de Ingenieros de Sistemas (Acis); gestor, fundador y expresidente de la Red de Decanos y Directores de Ingeniería de Sistemas (Redis). Columnista de Computerworld y eltiempo.com. Autor de 180 artículos y los siguientes libros: "GNU/Linux y el software libre"; Software libre una visión"; "Notas hacia un ecosistema inteligente"; "Sociedad transformada" y por publicar "Ciencias y tecnologías para la vida". 